\title{
Evidence live 2013
}

\section{Derek Richards}

Centre for Evidence-based Dentistry, Oxford

The Evidence Live Conference organised by the BMJ Group and the Oxford Centre for Evidence-based Medicine this year took place in Oxford.

The two day programme had a good mixture of plenary, parallel and poster sessions which gave participants ample opportunity to experience a wide range of what is happening at the leading edge of evidence-based healthcare in the world today. Naturally much of the meeting focus was around medical issues but the key methodological issues and challenges presented affect us equally in oral health.

With such an extensive programme (which is still available to view on the Evidence Live 2013 website). I am just going to pick out a few of my favourites.

Sir Muir Gray, is the first of three keynote speakers on the first morning. Sir Muir, who is the first Chief Knowledge Officer for the NHS and Director of the Oxford Centre for Health Care Transformation and one of the early pioneers of Evidence-based Health care, spoke about revolutions in medicine and the need to develop effective systems to deliver care. This is a theme that Sir Muir has been developing over the years and further information about this can be found on his

Better Value Health Care solutions website (http://www.ocht.net/).

The second keynote speaker was Peter Gotzche from the Nordic Cochrane Centre, who spoke about the case against screening for breast cancer. I find the fact that elements of this well established screening programme, where there is a considerable amount of evidence available, are coming into question, is interesting, bearing in mind the pressure that is building in some areas for formal oral cancer screening programmes to be introduced, particularly in the absence of good evidence for its effectiveness. ${ }^{1}$

Howard Buchner, the editor in chief of Journal of the American Medical Association, spoke eloquently on the problems of scientific integrity in scholarly research and the challenge that this presented for publishers. There was a sub-theme that ran through the two days, with Sir Michael Rawlins, the outgoing chair of the National Institute of Health \& Clinical Excellence (NICE) speaking about the role of the pharmaceutical industry in guidance development and whether they were saints or sinners. On the second day Peter Wilmhurst gave a heartfelt personal view of research misconduct in the pharmaceutical and medical devices industries, with Brian Deer, an investigative journalist (http://briandeer.com/) who was involved in the uncovering of the Andrew Wakefield story, bringing the formal proceedings to a close with an entertaining and thought provoking summary of his story.

Deciding which of the parallel sessions to attend is always difficult, particularly with so many high-quality speakers and topics on offer. As noted in the Evidence live blog, despite evidence-based health care being considered by some an elitist movement, participants were not afraid to challenge organisations like the august Cochrane Collaboration to do better and be more responsive, even

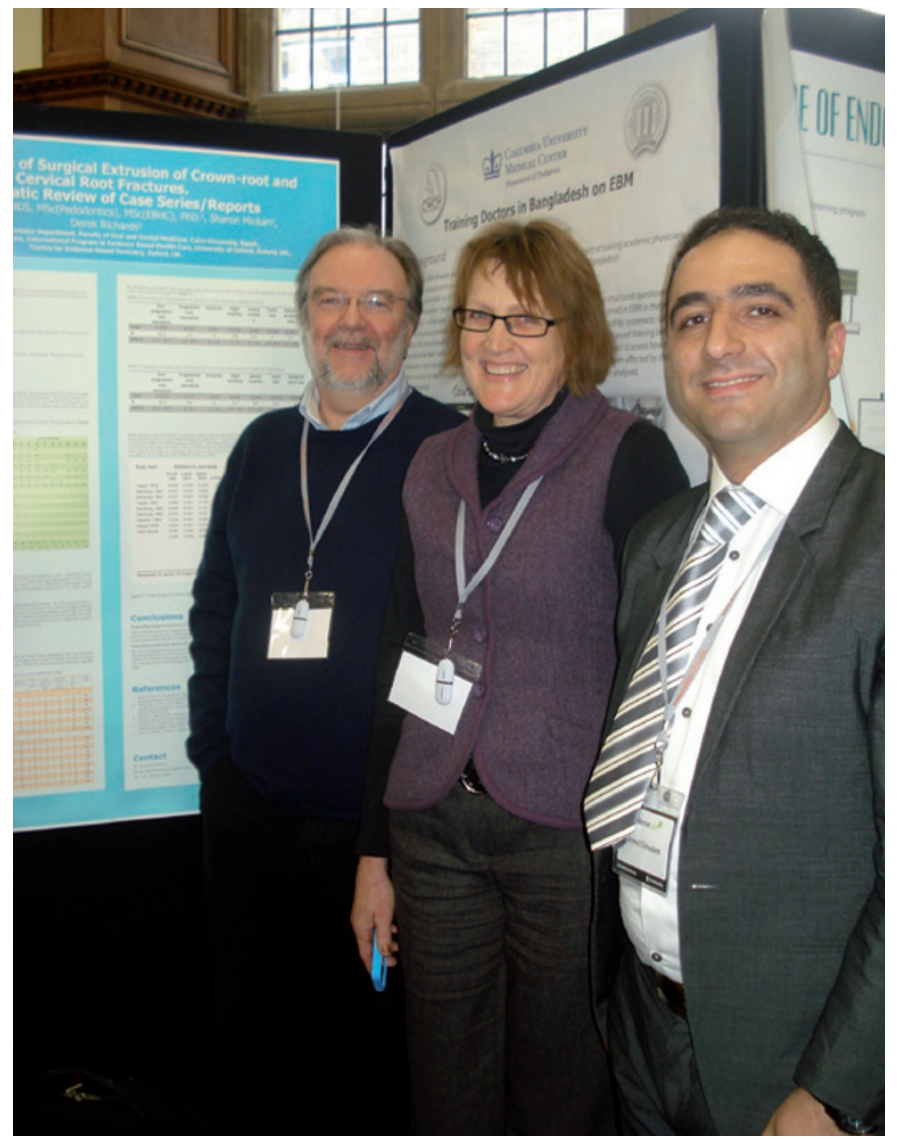

The Editor with colleagues from the Oxford MSc Programme in Evidence-based Health Care, Dr Sharon Mickan (Oxford) and Dr Ahmed Hosni (Egypt)

with the likes of the Editor-in-Chief of The Cochrane Library David Tovey, and the Director of the UK Cochrane Centre Martin Burton sitting in the room.

Another encouraging sign was the increase in the number of poster submissions; a list of these is available on the Evidence-live 2012 website, including one dental poster from dentists on the Oxford Master's Programme (see picture).

Readers can get a flavour of the conference by visiting the highlights page of the Evidence-live 2013 website.

A number of free talks are available by following the link to the Centre for Evidence-based Medicine You Tube channel including one on Evidence-based Dentistry from myself.

A particular favourite of mine is the one from David Speigelhalter on communicating risk and uncertainty.

http://www.evidencelive.org/2013/highlights

1. Rethman MP, Carpenter W, Cohen EE, et al. American Dental Association Council on Scientific Affairs Expert Panel on Screening for Oral Squamous Cell Carcinomas. Evidence-based clinical recommendations regarding screening for oral squamous cell carcinomas. J Am Dent Assoc 2010; 141: 509-520.

Evidence-Based Dentistry (2013) 14, 34. doi:10.1038/sj.ebd.6400924 